\title{
Clinical and genetic features of nonsyndromic autosomal dominant sensorineural hearing loss: KCNQ4 is a gene responsible in Japanese
}

Received: January 16, 2001 / Accepted: March 15, 2001

\begin{abstract}
Sixteen Japanese nonsyndromic autosomal dominant sensorineural hearing loss (ADSNHL) families were investigated clinically as well as genetically. Most families showed postlingual hearing loss. Although the severity of their hearing loss varied, most patients showed mildmoderate sensorineural hearing loss of a progressive nature. Mutation analysis was performed for the MYO7A, $K C N Q 4$, and GJB3 genes, which are known to be responsible for autosomal dominant sensorineural hearing loss. The present study reports that a mutation in $K C N Q 4$, a member of a large family of potassium channel genes, was responsible for ADSNHL in one Japanese family.
\end{abstract}

Key words Autosomal dominant $\cdot$ Nonsyndromic hearing loss $\cdot M Y O 7 A \cdot K C N Q 4 \cdot G J B 3$

\section{Introduction}

Recent molecular genetic studies have revealed the genes responsible for hereditary hearing impairment, and it has become possible to diagnose various types of hearing loss from the molecular genetic viewpoint. This is noteworthy because of the possible molecular diagnostic applications for individual affected patients.

For example, several reports have demonstrated that GJB2 accounts for the majority of autosomal recessive sensorineural hearing loss (ARSNHL) in several regions, including European countries (Denoyelle et al. 1997), the United States (Kelley et al. 1998), Japan (Abe et al. 2000),

J. Akita $\cdot$ S. Abe $\cdot$ H. Shinkawa

Department of Otorhinolaryngology, Hirosaki University School of Medicine, Hirosaki, Japan

W.J. Kimberling

Department of Genetics, Boys Town National Research Hospital, Omaha, NE, USA

S. Usami $(\square)$

Department of Otorhinolaryngology, Shinshu University School of

Medicine, 3-1-1 Asahi, Matsumoto 390-8621, Japan

Tel. +81-263-37-2666; Fax +81-263-36-9164

e-mail: usami@hsp.md.shinshu-u.ac.jp and Korea (Park et al. 2000). This gene is currently considered to be the first gene to screen for ARSNHL.

In contrast, for autosomal dominant sensorineural hearing loss (ADSNHL; which accounts for $30 \%$ of nonsyndromic hereditary hearing loss), the clinical and genetic features of nonsyndromic ADSNHL are not yet fully understood. This is because, although 36 loci (DFNA1-36) and 11 genes for ADSNHL have already been reported, most were identified in only a single or a few families. It is therefore clinically important to know which genes are major causes of Japanese ADSNHL.

Currently, two loci, DFNA11 (Tamagawa et al. 1996) and DFNA16 (Fukushima et al. 1999), have been reported for Japanese ADSNHL. Furthermore, an in-frame 9-bp deletion of exon 22 of $M Y O 7 A$, which is responsible for Usher type 1b (USH1B) (Wiel et al. 1995) and DFNB2 (Liu et al. 1997a; Wiel et al. 1997), was demonstrated in a DFNA11 family (Liu et al. 1997b). This suggests that $M Y O 7 A$ is, possibly, a major cause of Japanese ADSNHL.

Although the number of individuals in each of the 16 families in the present study is too small to draw conclusions about DFNA loci, our preliminary linkage analysis (not shown) suggested that at least 1 family was compatible with linkage to the DFNA2 locus. Because this locus was recently reported to contain two genes responsible for hearing loss, $K C N Q 4$ and GJB3, mutation screenings for these two genes were performed to determine whether they are common genes responsible for Japanese ADSNHL.

Another aim of this study was to summarize the clinical data of ADSNHL to determine whether there is a general characteristic feature.

\section{Subjects and methods}

Subjects

Forty-four subjects from 16 independent ADSNHL families (with two or more generations affected) were analyzed both genetically and clinically. 
Clinical evaluation

Pure-tone audiometry was performed in all 44 subjects. The criterion used to consider an individual affected was bilateral sensorineural hearing loss of more than $30 \mathrm{~dB}$ in at least one frequency with pure-tone audiometry. Severity of hearing loss was evaluated by a three-frequency average of 500, 1000 , and $2000 \mathrm{~Hz}$. The age at onset, degree of hearing loss, and presence of progression, tinnitus, and vertigo were evaluated in all affected individuals. Some patients underwent computerized tomography (CT) scan examination for inner ear malformations. For a selected family, we performed detailed auditory and vestibular testing, including Békésy audiometry, short increment sensitivity index (SISI) test, distortion product otoacoustic emission (DPOAE) test, and caloric test.

\section{Genetic analysis}

Blood samples from the 16 Japanese ADSNHL families, obtained with informed consent, were used in this study. Control samples were obtained from 96 Japanese subjects with normal hearing.

\section{MYO7A}

MYO7A consists of 49 exons. Polymerase chain reaction (PCR) amplification primers flanking each exon (Weston et al. 1996; Lévy et al. 1997) were used. Heteroduplex analysis was performed as previously described (Weston et al. 1996). Samples showing abnormal bands on heteroduplex analysis were further analyzed by direct sequencing with an ABI 377 sequencer (Perkin Elmer, CA, USA).

\section{KCNQ4}

KCNQ4 consists of 14 exons. Each exon was amplified using intronic primers as described previously (Kubisch et al. 1999; Van Hauwe et al. 2000). Direct sequencing was carried out to detect the mutations.

\section{GJB3}

GJB3 consists of 1 exon. The details of the PCR amplification were as described previously (Xia et al. 1998). All samples were analyzed by direct sequencing.

\section{Results}

\section{Clinical features of ADSNHL}

All patients had hearing loss. Severity of hearing loss (three-frequency average of 500, 1000, and $2000 \mathrm{~Hz}$ ) varied from mild to profound; $31.8 \%$ of the patients showed mild hearing loss $(30-49 \mathrm{~dB}), 29.5 \%$ had moderate hearing loss
(50-69 dB), 13.6\% had severe hearing loss (70-89dB), and $15.9 \%$ had profound hearing loss $(>90 \mathrm{~dB})$. The age at onset also varied, from congenital to the fifties. Twenty-four persons $(55 \%)$ had progressive loss, 15 persons $(34 \%)$ had tinnitus, and 10 persons (23\%) complained of vertigo. CT examination was performed for 31 patients, but no malformations of the inner ear were identified. Table 1 summarizes the clinical features of the present ADSNHL families.

Genetic analysis

\section{MYO7A}

Two polymorphic sites were identified: a $\mathrm{T} \rightarrow \mathrm{A}$ substitution at nucleotide position 4996 in exon 36, which converts cysteine residue at codon 1666 to serine, and a $\mathrm{A} \rightarrow \mathrm{C}$ substitution at nucleotide position 5860 in exon 43, which alters isoleucine at codon 1954 to leucine. But these two base changes were also detected in the 96 normal controls at a high frequency (C1666S, 41\% of alleles; I1954L, 66\% of alleles).

\section{KCNQ4}

In exon 5 of the $\mathrm{KCNQ}_{4}$ gene, a mutation of $\mathrm{G} \rightarrow \mathrm{C}$ was identified at nucleotide position 827 in the DFNA2compatible family, and this missense mutation leads to the replacement of tryptophan by serine (Fig. 1). This W276S mutation, which was not found in the 96 normal controls,

\begin{tabular}{lllllllllll}
\hline C & T & G & G & T & G & G & G & G & G & A
\end{tabular}
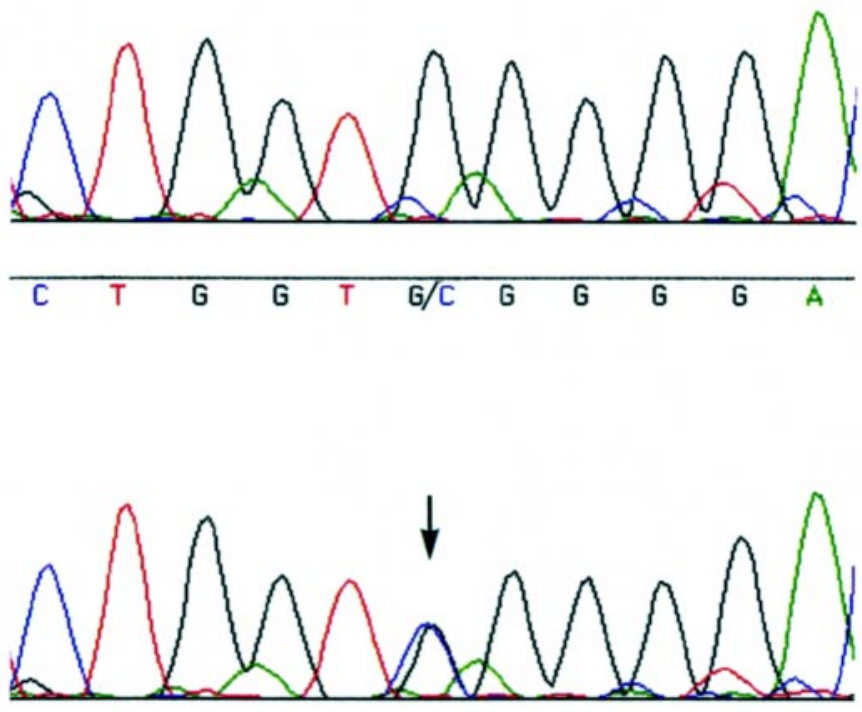

Fig. 1. Electrophoretogram showing W276S mutation (arrow). The Gto-C mutation at position $827(827 \mathrm{G} \rightarrow \mathrm{C})$ leads to the replacement of a tryptophan (Trp, W) residue at position 276 by serine (Ser, S) 


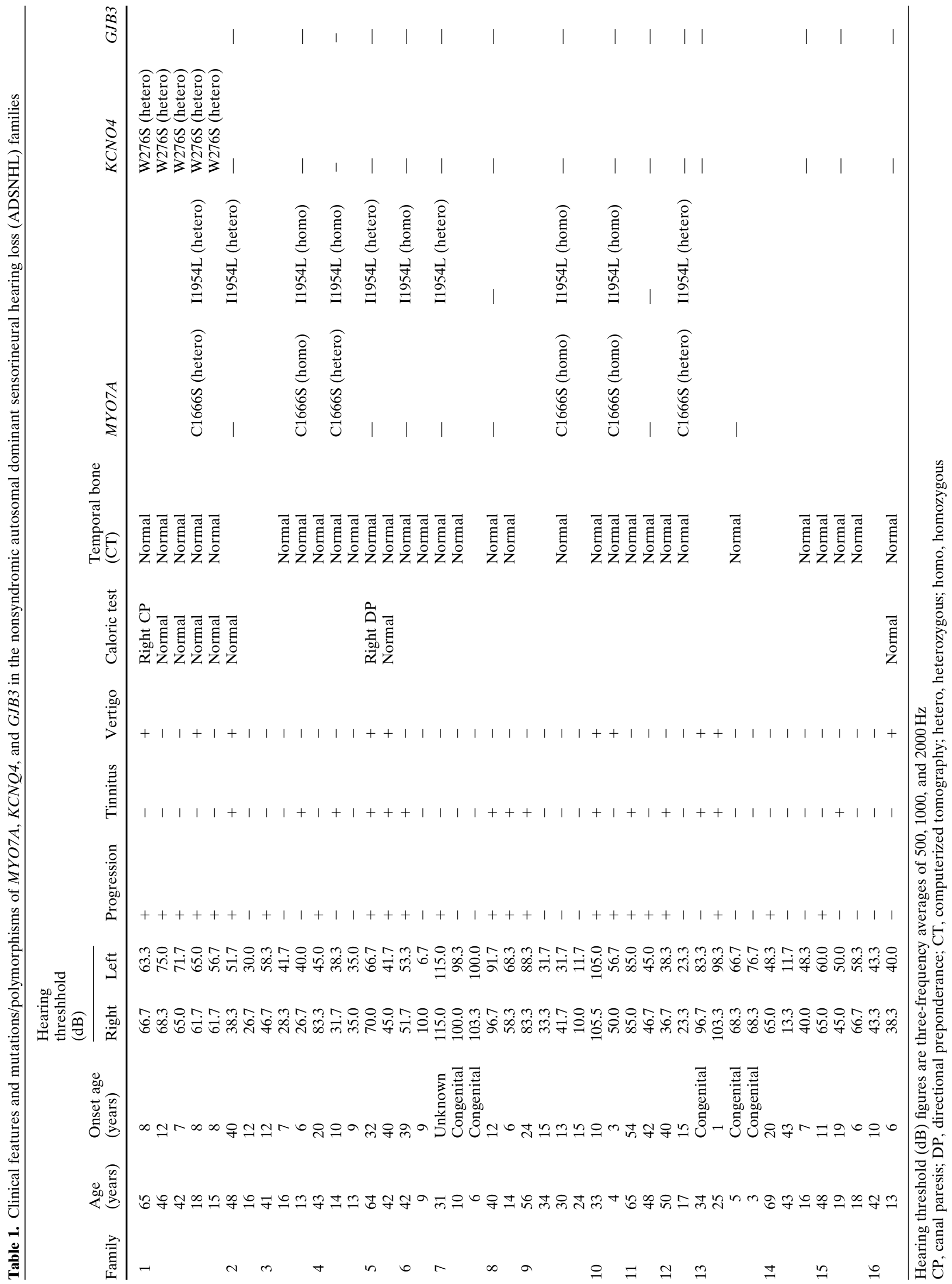




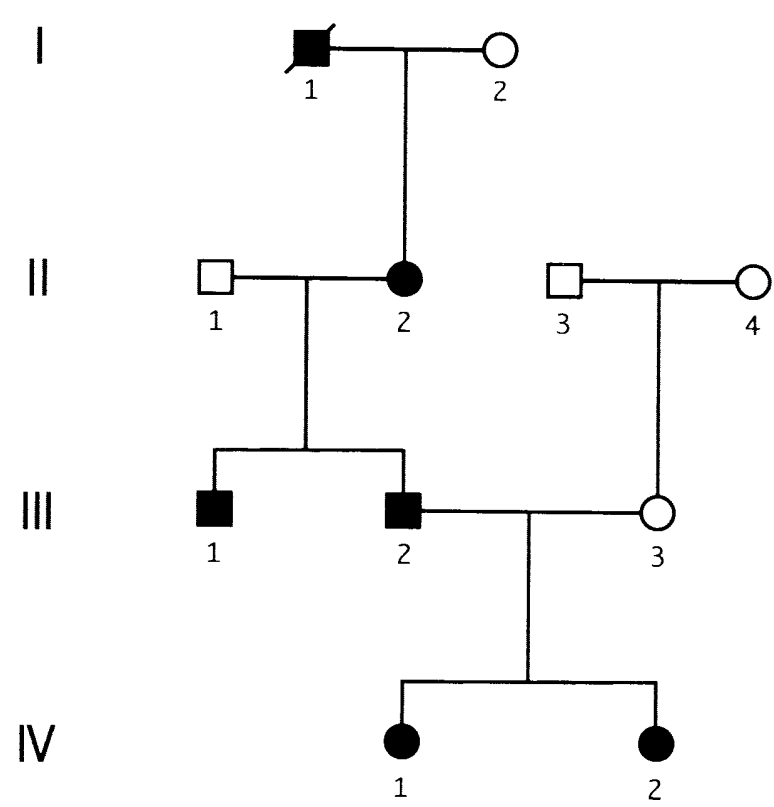

Fig. 2. Pedigree of the family bearing a $K C N Q 4$ mutation. Filled symbols represent affected members; Diagonal slash indicates deceased person

was highly segregated in the family, and all affected members had this mutation.

The pedigree of the family with the KCNQ4 mutation is shown in Fig. 2. This family was affected in four generations. Genetic as well as clinical evaluation was performed in seven members (five affected, two unaffected). The detailed audiometric data of the five affected members are summarized in Table 2. All the affected subjects presented a postlingual high frequencies-predominant hearing impairment that was not associated with tinnitus. They had noticed their hearing impairment at the age of 7-12 years, and had gradual progression. Audiograms of subjects IV-1 and IV-2 showed the progression of hearing loss over the testing period (Fig. 3). In all patients, Békésy audiograms showed a type II pattern, and a high SISI score was noted. The DPOAE response was not obtained in any affected patients. Two subjects reported vertigo. Caloric testing showed unilateral poor response in one subject (II-2) and one patient (IV-2) had an episode of epilepsy.

\section{GJB3}

No mutations were identified in the GJB3 gene.

\section{Discussion}

As show in Table 1, the present study revealed common as well as variable clinical features of ADSNHL. First, with regard to the onset of hearing loss, the majority (14 of the 16 families) showed postlingual rather than congenital loss. Secondly, individual hearing levels varied, but most $(61.4 \%)$ showed mild-moderate hearing loss. Patients with

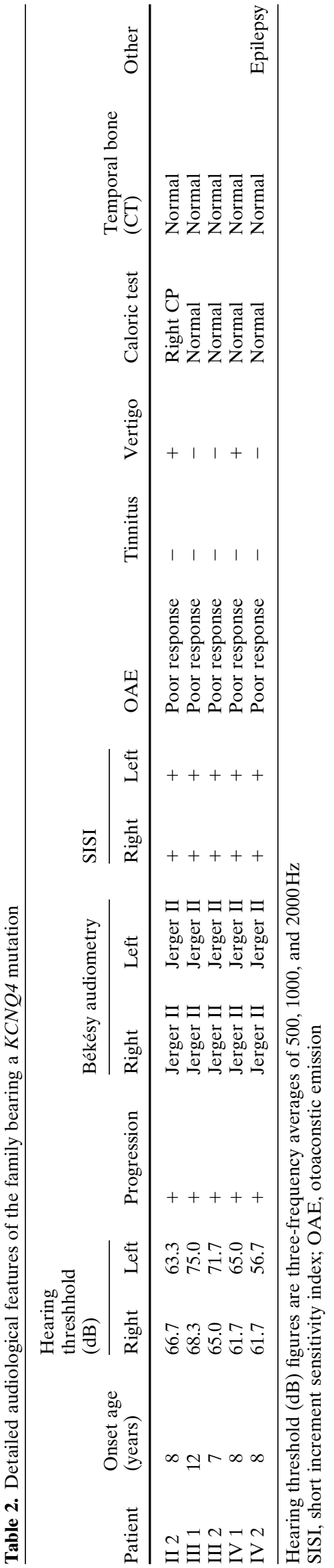



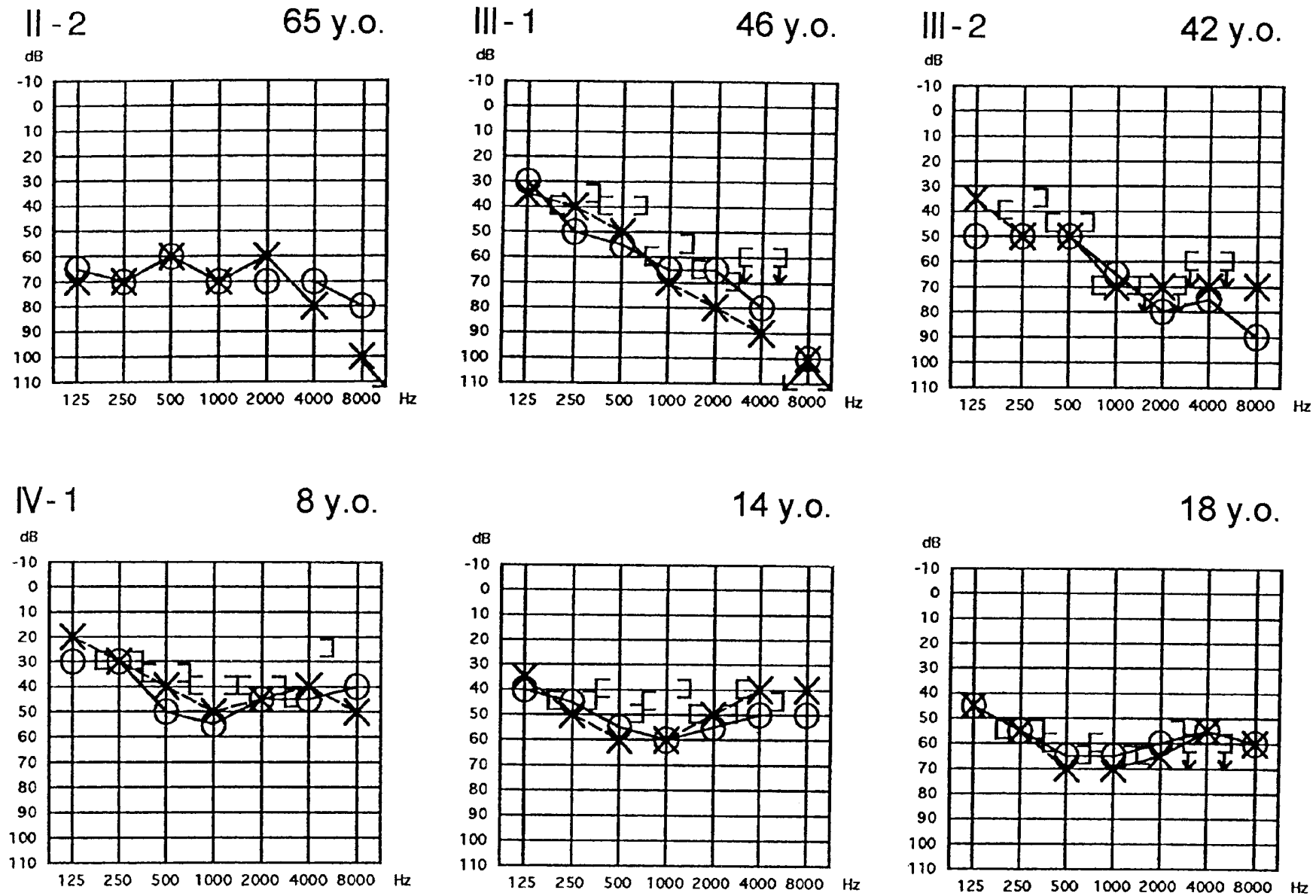

18 y.o.
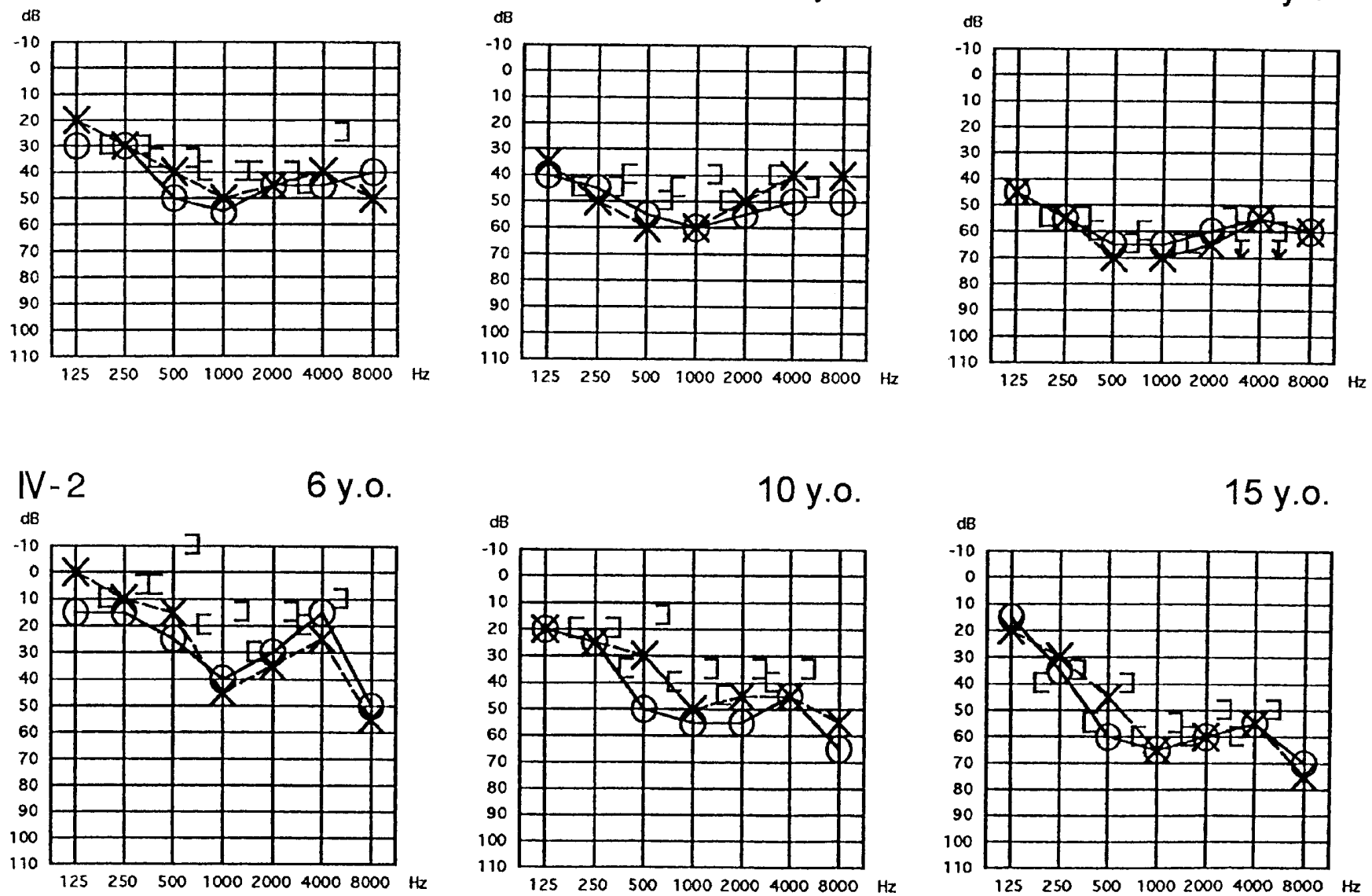

15 y.o.

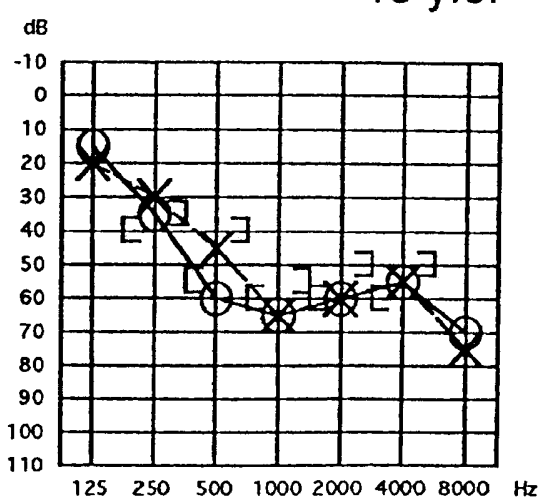

Fig. 3. Audiograms from family members showing high-frequencyinvolved sensorineural hearing loss. A collection of audiograms from two subjects (IV-1 and IV-2) showing progressive hearing loss is also

shown. Subject numbers are those shown in the pedigree in Fig. 2. y.o., Years old

severe-profound hearing loss (over $70 \mathrm{~dB}$ ) were usually older. Thirdly, most patients recognized progression of hearing loss. Patients who did not feel progression were young. No malformations of the inner ear were identified by CT examination, suggesting that the hearing loss was not caused by deformities of the inner ear. From the observation of these clinical features, ADSNHL has more or less common features, although there is still interindividual variation.

In the genetic analysis of the MYO7A gene, two base changes in exons 36 (C1666S) and 43 (I1954L) were identified. These mutations, however, were also detected in normal controls at a high frequency ( $41 \%$ of alleles for C1666S and $66 \%$ of alleles for I1954L). There was no significant 
difference in allele frequencies between the patient group and the controls. Therefore, in spite of the amino acid conversion, these mutations of the $M Y O 7 A$ gene are certainly polymorphisms, and not disease-causing mutations. Many polymorphic sites have been reported in the MYO7A gene (Weston et al. 1996; Janecke et al. 1999). The present results add two common polymorphic sites in MYO7A, and suggest that the $M Y O 7 A$ gene is unlikely to be the major gene responsible for Japanese ADSNHL.

The present study is the first to describe a mutation in the $K C N Q 4$ gene in Japanese with ADSNHL, the second gene after $M Y O 7 A$ reported to be responsible for ADSNHL in that population. $K C N Q 4$, a member of a large $\mathrm{K}^{+}$channel family, has been thought to play an important role in $\mathrm{K}^{+}$ recycling. An in-situ hybridization study has indicated that KCNQ4 mRNA is expressed in the inner ear hair cells (both cochlear and vestibular) (Kharkovets et al. 2000). At present, seven mutations of the KCNQ4 gene have been identified (Coucke et al. 1999; Kubisch et al. 1999; Talebizadeh et al. 1999; Van Hauwe et al. 2000). Five mutations have been found in exons coding for the $K C N Q 4$ P-loop domain (Talebizadeh et al. 1999; Van Hauwe et al. 2000). Interestingly, W276S, seen in our Japanese family, was also found in a Dutch family (Coucke et al. 1999). The fact that this mutation was found across racial differences suggests that this is, possibly, a mutational hotspot in the $K C N Q 4$ gene. On the other hand, there is a very slight possibility that the mutations may be related through a common ancestor. We have confirmed, by means of haplotype analysis, that the hotspot explanation is most likely (van Camp, manuscript in preparation). The W276S mutation, located in a critical domain of the protein, replaces tryptophan (W) by serine (S). Because it is necessary to aggregate four $K C N Q 4$ subunits to form a functional channel, this mutation may exert a dominant negative effect.

A W276S missense mutation in exon 5 of the $K C N Q 4$ gene was found in all affected family members. As shown in Table 2, all family members had postlingual onset (at the age of 7-12 years) and moderate-severe, progressive, highfrequency-involved sensorineural hearing loss. These audiological features of the patients with $K C N Q 4$ mutations are mostly in line with the previous reports on a Dutch family, and there were no significant differences between our findings and these in the Dutch family (see Van Hauwe, 1999 for review). As for the detailed audiometric evaluation, all family members showed Jerger type II Békésy audiometry findings, positive SISI test, and poor response to the DPOAE test, suggesting that the origin of their hearing loss was, most likely, the inner ear. Two of the affected family members had had episodes of vertigo. As $K C N Q 4$ is also expressed in vestibular hair cells (Kharkovets et al. 2000), it is conceivable that such vertigous symptoms are caused by vestibular dysfunction. One patient had had an episode of epilepsy. Epilepsy has been reported in patients carrying mutations of the KCNQ2 or KCNQ3 genes (Biervert et al. 1998; Charlier et al. 1998; Singh et al. 1998), which are members of the same $\mathrm{K}^{+}$channel family. Further discussion will be needed to reach a conclusion as to whether epilepsy is one component of $K C N Q 4$ mutation.
However, symptoms such as vertigo and epilepsy should be carefully taken into consideration when patients with ADSNHL are observed.

There were no mutations in GJB3 (connexin 31) in the families studied, suggesting that this gene may not be a major cause of Japanese ADSNHL.

To summarize, the present study revealed the first Japanese ADSNHL family associated with $K C N Q 4$. However, the gene responsible for ADSNHL in the majority of families remains unclear, and no common genes causing ADSNHL have been reported. Efforts should be continued to find such a common gene. It is also possible that there is no such single common gene, but that many genes contribute to ADSNHL; in other words, ADSNHL may exhibit genetic heterogeneity. The variable clinical features of the condition may support this idea.

Acknowledgements We thank all the families that participated in the present project. We would also like to thank Ms. C. Kawashima and Ms. T. Matsukura for technical assistance, and Ms. A.C. AppleMathews for help in preparing the manuscript. This work is supported by the Ministry of Health and Welfare of Japan (S.U.), and by a Grantin-Aid for Scientific Research from the Ministry of Education, Science, and Culture of Japan (S.U.).

\section{References}

Abe S, Usami S, Shinkawa H, Kelley PM, Kimberling WJ (2000) Prevalent connexin 26 gene (GJB2) mutations in Japanese. J Med Genet 37:41-43

Biervert C, Schroeder BC, Kubisch C, Berkovic SF, Propping P, Jentsch TJ, Steinlein OK (1998) A potassium channel mutation in neonatal human epilepsy. Science 279:403-406

Charlier C, Singh NA, Ryan SG, Lewis TB, Reus BE, Leach RJ, Leppert M (1998) A pore mutation in a novel KQT-like potassium channel gene in an idiopathic epilepsy family. Nature Genet 18:5355

Coucke PJ, Van Hauwe P, Kelly PM, Kunst H, Schatteman I, Van Velzen D, Meyers J, Ensink RJ, Verstreken M, Declau F, Marres H, Kastury K, Bhasin S, McGuirt WT, Smith RJH, Cremers CWRJ, Van de Heyning P, Willems PJ, Smith SD, Van Camp G (1999) Mutations in the $K C N Q 4$ gene are responsible for autosomal dominant deafness in four DFNA2 families. Hum Mol Genet 8:1321-1328

Denoyelle F, Weil D, Maw MA, Wilcox SA, Lench NJ, Allen-Powell DR, Osborn AH, Dahl HHM, Middleton A, Houseman MJ, Dodé C, Marlin S, Boulila-ElGaïed A, Grati M, Ayadi H, BenArab S, Bitoun P, Lina-Granade G, Godet J, Mustapha M, Loiselet J, El-Zir E, Aubois A, Joannard A, Levilliers J, Garabédian EN, Mueller RF, Gardner RJM, Petit C (1997) Prelingual deafness: high prevalence of a 30 delG mutation in the connexin 26 gene. Hum Mol Genet 6:21732177

Fukushima K, Kasai N, Ueki Y, Nishizaki K, Sugata K, Hirakawa S, Masuda A, Gunduz M, Ninomiya Y, Masuda Y, Sato M, McGuirt WT, Coucke P, Van Camp G, Smith RJH (1999) A gene for fluctuating, progressive autosomal dominant nonsyndromic hearing loss, DFNA16, maps to chromosome 2q23-24.3. Am J Hum Genet 65:141-150

Janecke AR, Meins M, Sadeghi M, Grundmann K, Apfelstedt-Sylla E, Zrenner E, Rosenberg T, Gal A (1999) Twelve novel myosin VIIA mutations in 34 patients with Usher syndrome type I: confirmation of genetic heterogeneity. Hum Mutat 13:133-140

Kelley PM, Harris DJ, Comer BC, Askew JW, Fowler T, Smith SD, Kimberling WJ (1998) Novel mutations in the connexin 26 gene (GJB2) that cause autosomal recessive (DFNB1) hearing loss. Am J Hum Genet 62:792-799

Kharkovets T, Hardelin JP, Safieddine S, Schweizer M, El-Amraoui A, Petit C, Jentsch TJ (2000) KCNQ4, a $\mathrm{K}^{+}$channel mutated in 
a form of dominant deafness, is expressed in the inner ear and the central auditory pathway. Proc Natl Acad Sci USA 97:43334338

Kubisch C, Schroeder BC, Friedrich T, Lütjohann B, El-Amraoui A, Marlin S, Petit C, Jentsch TJ (1999) KCNQ4, a novel potassium channel expressed in sensory outer hair cells, is mutated in dominant deafness. Cell 96:437-446

Lévy G, Levi-Acobas F, Blanchard S, Gerber S, Larget-Piet D, Chenal V, Liu XZ, Newton V, Steel KP, Brown SDM, Munnich A, Kaplan J, Petit C, Weil D (1997) Myosin VIIA gene: heterogeneity of the mutations responsible for Usher syndrome type1B. Hum Mol Genet 6:111-116

Liu XZ, Walsh J, Mburu P, Kendrick-Jones J, Cope MJTV, Steel KP, Brown SDM (1997a) Mutations in the myosin VIIA gene cause nonsyndromic recessive deafness. Nature Genet 16:188-190

Liu XZ, Walsh J, Tamagawa Y, Kitamura K, Nishizawa M, Steel KP, Brown SDM (1997b) Autosomal dominant non-syndromic deafness caused by a mutation in the myosin VIIA gene. Nature Genet 17:268-269

Park HJ, Hahn SH, Chun YM, Park K, Kim HN (2000) Connexin 26 mutations associated with nonsyndromic hearing loss. Laryngoscope 110:1535-1538

Singh NA, Charlier C, Stauffer D, DuPont BR, Leach RJ, Melis R, Ronen GM, Bjerre I, Quattlebaum T, Murphy JV, McHarg ML, Gagnon D, Rosales TO, Peiffer A, Anderson VE, Leppert M (1998) A novel potassium channel gene, $K C N Q 2$, is mutated in an inherited epilepsy of newborns. Nature Genet 18:25-29

Talebizadeh Z, Kelley PM, Askew JW, Beisel KW, Smith SD (1999) Novel mutation in the $K C N Q 4$ gene in a large kindred with dominant progressive hearing loss. Hum Mutat 14:493-501
Tamagawa Y, Kitamura K, Ishida T, Ishikawa K, Tanaka H, Tsuji S, Nishizawa M (1996) A gene for a dominant form of non-syndromic sensorineural deafness (DFNA11) maps within the region containing the DFNB2 recessive deafness gene. Hum Mol Genet 5:849-852

Van Hauwe P, Coucke PJ, Van Camp G (1999) The DFNA2 locus for hearing impairment: two genes regulating $\mathrm{K}^{+}$ion recycling in the inner ear. Br J Audiol 33:285-289

Van Hauwe P, Coucke PJ, Ensink RJ, Huygen P, Cremers CWRJ, Van Camp G (2000) Mutations in the $K C N Q 4 \mathrm{~K}^{+}$channel gene, responsible for autosomal dominant hearing loss, cluster in the channel pore region. Am J Med Genet 93:184-187

Weston MD, Kelley PM, Overbeck LD, Wagenaar M, Orten DJ, Hasson T, Chen ZY, Corey D, Mooseker M, Sumegi J, Cremers C, Möller C, Jacobson SG, Gorin MB, Kimberling WJ (1996) Myosin VIIA mutation screening in 189 Usher syndrome type 1 patients. Am J Hum Genet 59:1074-1083

Wiel D, Blanchard S, Kaplan J, Guilford P, Gibson F, Walsh J, Mburu P, Varela A, Levilliers J, Weston MD, Kelley PM, Kimberling WJ, Wagenaar M, Levi-Acobas F, Larget-Piet D, Munnich A, Steel KP, Brown SDM, Petit C (1995) Defective myosin VIIA gene responsible for Usher syndrome type 1B. Nature 374:60-61

Wiel D, Küssel P, Blanchard S, Lévy G, Levi-Acobas F, Drira M, Ayadi H, Petit C (1997) The autosomal recessive isolated deafness, DFNB2, and the Usher 1B syndrome are allelic defects of the myosin VIIA gene. Nature Genet 16:191-193

Xia JH, Liu CY, Tang BS, Pan Q, Huang L, Dai HP, Zhang BR, Xie W, Hu DX, Zheng D, Shi XL, Wang DA, Xia K, Yu KP, Liao XD, Feng Y, Yang YF, Xiao JY, Xie DH, Huang JZ (1998) Mutations in the gene encoding gap junction protein $\beta-3$ associated with autosomal dominant hearing impairment. Nature Genet 20:370-373 